\title{
A ilha de Sokúrov no cinema da Glasnost: isolamento e comunicação como hipóteses interpretativas da obra de Alexandr Sokúrov
}

\section{Marcos Kahtalian}

Pontifícia Universidade Católica, Programa de Pós-Graduação em Comunicação e Semiótica, São Paulo, SP, Brasil

ORCID: https://orcid.org/0000-0003-3899-8876

\section{Leda Tenório da Motta}

Pontifícia Universidade Católica, Programa de Pós-Graduação em Comunicação e Semiótica, São Paulo, SP, Brasil

ORCID: https://orcid.org/0000-0002-1468-4752

\section{Resumo}

O artigo formula uma pequena história da obra do cineasta russo Alexandr Sokúrov contextualizado esta obra dentro de um panorama de cinema da Glasnost, o período de dissolução do regime soviético. Trata-se de mostrar como ela é marcada pela necessidade de firmar uma autoria, primeiro dentro de um contexto adverso de estado, depois dentro de um regime de mercado. É inseparável disso assinalar como é ainda percorrida por uma certa tensão dialética entre isolamento e comunicação, a sugerir a hipótese de uma poética distinguida pela ideia metafórica de ilha. Os referenciais teóricos abrangem a fortuna crítica disponível dentro e fora da Rússia, com destaque para os estudos pioneiros realizados internacionalmente por François Albéra e Diane Arnaud, e aportes dos formalistas russos no campo da poética do filme, com destaque para Boris Eikhenbaum.

\section{Palavras-chave}

Cinema. Cinema Russo. Sokúrov. Glasnost. 


\section{Uma pequena história e a tensão dialética de Alexandr Sokúrov no período da Glasnost}

O cineasta russo Alexandr Sokúrov (1951-) surge no contexto de dissolução da União das Repúblicas Socialistas Soviéticas (URSS) quando em 1975, aos 24 anos, ingressa no prestigioso Instituto Estatal de Ensino de Cinema Moscovita (VGIK) onde Eisenstein lecionou, após concluir uma graduação inicial em História na Universidade de Górki, hoje Níjni Novgórod. Antes deste ingresso no VGIK, vale ressaltar, Sokúrov trabalhou em na cidade de Górki, durante seis anos, como assistente técnico de produção na televisão estatal local, participando da realização de documentários e tendo ali iniciado a realização do que seria posteriormente considerado seu primeiro filme de não-ficção, Maria, Elegia Camponesa (1978).

Tal iniciação terá sido marcante para o artista, não apenas por sua grande dedicação a filmes documentários - o número de filmes de não-ficção é quase o dobro dos seus filmes de ficção - mas também, como aponta o estudioso de cinema russo François Albéra, pela indistinção entre os dois grandes gêneros com que joga Sokúrov, inclusive, filmando em suportes de Vídeo e exclusivamente para a Televisão. Albéra sugere que, talvez, devido a esse início documental, Sokúrov tenha escolhido a graduação no VGIK na categoria de filmes pedagógicos, como eram chamados no período, sendo estes normalmente exibidos nas salas como primeira parte dos programas e voltados a conteúdos instrutivos como vida animal e pragas no campo, entre outros (ALBÉRA; ESTÈVE, 2009).

Temos em Nancy Condee (2009), especialista em cinema russo, uma interessante reconstituição cruzada desse período de formação. Ela evoca um antigo companheiro do diretor, Liúbov Arkus, importante crítico de São Petersburgo, que atesta que o jovem cineasta era então conhecido por sua disciplina de ferro e alto ativismo social, referindo-se ao fato como sendo entusiasmos de um neófito. É nesse mesmo momento formativo que Sokúrov declara sua admiração por A Greve (1925) de Eisenstein e passa seu período de estudos tendo obtido a bolsa de estudos Eisenstein, para jovens talentos de alto desempenho acadêmico. Não se pode duvidar do comprometimento de Sokúrov com a questão socialista (e uma bolsa de estudos no estado soviético não ocorria sem pertinência), nessa época, não apenas pela sua graduação em História, sua dedicação a filmes didáticos, o depoimento de colegas, mas sobretudo por um fato que explicita esse comprometimento: sua eleição, pelos estudantes, para o cargo de secretário geral do Konsómol (a organização 
para a juventude do Partido Comunista) do Instituto de Realizadores. Tudo leva a crer, portanto, em uma perfeita integração com o universo do Estado Soviético.

Albéra (ALBÉRA; ESTÈVE, 2009) repara, porém, que, nesta época, e em razão de seu ativismo, Sokúrov envolveu-se em inúmeros conflitos com a direção do Instituto, reivindicando melhores condições de estudo, denunciando os professores como incompetentes e absenteístas. Talvez por isso, pondera, seu filme de formação, concluído dois anos depois (e um ano antes do prazo regular para formação, note-se), A Voz Solitária do Homem (1978), conhece acidentado percurso que favorecerá a percepção de isolamento do cineasta. Este filme, após ser recusado como prova final da maestria acadêmica, só é liberado comercialmente em 1987, após conhecidos esforços de outro cineasta russo, Andrei Tarkóvski, que solicita um novo exame de julgamento da obra, reconhecendo-lhe grandes méritos artísticos, de tal forma que, em 1987, o mesmo conquista o prêmio principal no XI Festival de Locarno, na Suíça.

Contudo, apesar do prêmio, Sokúrov não estaria presente à solenidade de formatura de sua turma no VGIK, sendo graduado como aluno externo. Tal fato, no contexto de um sistema de produção controlado pelo Estado, traz inúmeros problemas, a começar pelo mais básico que seria a inscrição sindical do cineasta e a consequente autorização formal para dirigir filmes produzidos pelo governo. Em uma nação com forte controle central, o diploma é um dos documentos fundamentais para a própria viabilidade econômica do cineasta e para a capacidade produtiva do realizador, visto que não existem outros meios de produção disponíveis. Nesse contexto, desagradar ao regime equivalia a lançar um interdito sobre sua produção, se não por motivos burocráticos, como neste caso de Sokúrov, também por razões de visada artística, como no caso de Tarkóvski, fadado a recorrer a financiamentos internacionais, cineasta a quem o próprio Sokúrov, dedica uma de suas elegias, Elegia de Moscou (1986).

Note-se que, com mais ou menos detalhes, esta crônica da gênese artística acidentada de Sokúrov será recontada por todos os comentadores e historiadores de sua obra, como Álvaro Machado (2002), Bruno Dietsch (2005) e François Albéra (2009).

Trata-se de uma história fundadora do mito do "cineasta dos cineastas, autor de autores" (BRASHINSKY; HORTON, 1994, pg. 121), onde este filme de formação tornou-se, segundo se dizia, um "filme não visto, um filme fantasma, um filme lenda, um filme rumor" (CONDEE, 2009, p. 162, tradução nossa). 
Como ressalta Albéra (ALBÉRA; ESTÈVE, 2009), é bem provável que parte da rejeição inicial a Sokúrov dentro do cinema ainda sob a égide do Regime Soviético tenha sido provocada pela sua insubordinação - atitude aliás ainda característica do diretor ${ }^{1}$ mas também, acrescente-se, a um deliberado posicionamento estético, ele mesmo, por oposição a uma certa concepção dominante de cinema naquele momento. Isto pode talvez ser melhor evidenciado pelo fato de que A Voz Solitária do Homem (1978), filme de ficção de estreia, é apresentado como filme de formação na cadeira de filmes pedagógicos, vale dizer, científicos, quando o esperado, segundo Albéra (ALBÉRA; ESTÈVE, 2009), seria a apresentação de um documentário tradicional sobre o escritor Andrei Platónov, com uma duração média de 20 minutos.

Surpreendentemente, em vez de narrar a biografia de Platónov, Sokúrov resolve adaptar, de forma livre e fragmentária, um seu romance, O Rio Potudan, de 1937 (PLATONOV, 1988) - o mesmo livro que Andrei Mikhálkov-Konchalovski adaptaria, posteriormente, nos EUA com o nome de Os Amantes de Maria (1984), sem mencionar a fonte. Ora, fazer um filme de ficção quando se espera um documentário será no mínimo uma provocação, e se se quiser, uma forma de marcar uma diferença, uma individualidade. Nesse sentido, Sokúrov ao inverter as expectativas naturais que se esperaria de um filme documental, ao fazer do tema documental um filme de ficção, colocava-se, acredita-se, em relativo risco de julgamento pelo estado soviético. 0 resultado é que o filme foi recusado como projeto de formatura e o mesmo somente escapou de ser destruído - conforme ordenado pela própria Mosfilm e pelo VGIK, por que foi escondido por colegas de Sokúrov, entre os quais Iuri Arábov, colaborador habitual de seus roteiros. ${ }^{2}$

\footnotetext{
1 Estes conflitos não são incomuns na carreira do diretor. Em 2010, no festival de Cannes, Sokúrov foi um dos signatários da moção contrária ao filme $O$ Sol Enganador (1994) de Nikita Mikhalkov, por não representar a Rússia e pelo suposto uso de recursos desviados do estado. A briga e a oposição com Mikhalkov, cineasta que já presidiu a União de Cineastas é conhecida no meio de cinema russo e Albera (ALBÉRA; ESTÈVE, 2009) chega mesmo a fazer dos dois realizadores emblemáticos de pólos opostos - Mikhalkov, mais comercial e sempre tendo desejado agradar o grande público, e Sokúrov um cineasta comprometido apenas com sua própria obra. Uma dicotomia que persiste na crítica.

2 Nancy Condee (2009) comenta que os colegas de Sokúrov teriam tentado aprová-lo no VGIK com um documentário feito ainda na época da televisão em Górki, o filme $O$ verão de Maria Voinova (1975) e outros colegas aludem para um obscuro filme quase nunca mencionado em sua filmografia, um típico documentário técnico, Os Automóveis Ganham Confiança (1977) também para a televisão.
} 
Tão consumada se encontra essa lenda nos estudos sokurovianos, que se presta àquela outra interessante fala do personagem de ficção que nos alerta para o fato de que, quando a lenda for maior do que a verdade, imprima-se a lenda. ${ }^{3}$

O que se pretende, portanto, com esta análise contextual de Sokúrov, é demonstrar estes fatores de isolamento do cineasta, associando esta posição a uma certa recorrência da ilha em sua obra, mesmo quando desponta sob o aspecto de seu contrário aparente, o avassalamento contagiante, a dimensão portuária do mar ao redor da ilha. Trata-se de assinalar como, pela força de uma instigante interconexão entre circunstância biográfica e marca autoral, um cineasta classificado como pós-soviético, e nesse sentido alijado daquela "lógica da arte comunista" (BAZIN, 2014, p. 61) de que falava André Bazin, crítico pioneiro do mito de Stalin, é suscetível de ser visto emergindo das ruínas desse mesmo estado de coisas.

Há um termo para isso nos estudos cinematográficos russos, correntemente observado por parte da principal historiografia russa de cinema, que chama ao período em apreço, de debâcle do regime soviético, de "Cinema da Glasnost" (BRASHINSKY; HORTON, 1994, p. 1-8). Embora cronologicamente a obra de Sokúrov apareça no final do que é conhecido como período de estagnação (a era Brejnev), ela se desenvolve de fato com a Perestroika, no período liderado por Gorbatchóv (BEUMERS, 2009). Obviamente, como qualquer periodização histórica, esta também carrega marcas de sua circunstância; no caso inscreve-se no quadro mais geral das lutas pela liberalização do regime - um quadro político, social e cultural amplo que, como procurou demonstrar Boris Schnaiderman (1997), aglutinou forças e sentimentos díspares e fez ruir o grande império soviético, de forma não bem prevista, gerando toda uma descoberta das artes e obras não conhecidas, inclusive a obra de Sokúrov.

Convém lembrar que a noção mesma de império (e no caso de império esfacelado), de grande país continental que se descortina para além do centro russo, em inúmeras regiões controladas, é um traço do cinema de Sokúrov ${ }^{4}$ assim como de grande parte do cinema russo, como um centro temático, conforme procurou demonstrar Nancy Condee

\footnotetext{
3 Referência ao personagem de James Stewart em O Homem que Matou o Facínora (The man who shoot Liberty Valance, 1962), de John Ford. 0 roteirista habitual de Sokúrov, Iuri Arabov, colega desta época, amplia esta lenda da origem, em tintas “cinematográficas" ao comentar (apud CONDEE, 2009, p. 281) como o filme a Voz Solitária do Homem (1978), cuja cópia e negativo foram mandados para serem destruídos pelo VGIK e Mosfilm foram secretamente retirados da sala de montagem na hora da destruição e substituídos por 0 Encouraçado Potemkim! Que, segundo Arabov, poderia ter sido perfeitamente destruído pelos funcionários do VGIK, e imagine-se o papelão! Segundos consta o filme de Sokúrov ficou escondido na casa do também colega e cineasta Alexei German.

4 Nancy Condee (2009): enxerga o traço imperial em muitos filmes de Sokúrov, mas confere especial destaque à trilogia sobre o poder (Moloch, 1999, Taurus, 2001 e O Sol, 2005) e a Arca Russa (2002).
} 
(2009) no seu livro muito apropriadamente intitulado The Imperial Trace - Recent Russian Cinema $^{5}$

A Glasnost, ou Transparência, pode ser entendida como um processo de liberalização do estado soviético, que, juntamente com a Perestroika, ou Reformulação, presidiram à passagem de um conjunto fortemente integrado de Repúblicas Socialistas sob a tutela de Moscou para um Estado Russo fragmentado e federado, em um período relativamente curto, de 1985 até 1991, ano em que finalmente a URSS foi dissolvida. Este período foi precedido, acompanhado e sucedido por um conjunto de manifestações culturais - entre as quais o cinema - que de modo geral propunham um processo de maior liberdade criativa, menor censura, com novas temáticas, questões amplamente apoiadas por Gorbachóv, inclusive no âmbito do cinema, com a reformulação dos quadros da União de Cineastas do país (BRASHINSKY; HORTON, 1994).

Se a Glasnost trouxe a liberalização da produção, inclusive com a admissão de Sokúrov, agora legalmente, no quadro de diretores da União de Cineastas da Rússia, conferindo-lhe autorização formal para a captação de recursos e distribuição de suas obras, paralelamente, a dissolução do estado soviético gerou o desmantelamento da produção. Em média eram produzidas quase 400 obras para o cinema por ano até 1991 na URSS. Após 1991 este número caiu para menos de uma centena (ALBÉRA; ESTÈVE, 2009).

Desta forma, por um efeito talvez perverso, com a Glasnost, os cineastas das antigas repúblicas socialistas soviéticas se viram, de um lado, com toda a liberdade possível para fazer o que bem pretendiam, de outro, sem nenhum dinheiro para fazê-lo. É que, por decisão da nova ordem econômica, o estado até então onipresente, que dominava da produção à distribuição e exibição, retirou-se abruptamente, deixando o campo livre, de tal sorte que, como no modelo ocidental, os filmes seriam agora patrocinados por produtores privados que deveriam auferir lucro com essa atividade ${ }^{6}$. Esta situação na qual emergia a liberdade e o primado do autor, originando um renascimento artístico do qual Sokúrov é dos mais proeminentes representantes, (BEUMERS, 2009), coloca em questão as várias concepções de cinema: primado do mercado, primado da arte, cinema comercial, cinema de autor, fontes públicas e privadas de financiamento, entre outros polos de debate no cenário pós-soviético.

5 CONDEE, Nancy. The Imperial Trace: recent russian cinema. Oxford: Oxford Press, 2009.

60 problema, é claro, é que este desmonte apenas desmascarou o que o Estado Soviético subsidiava, pois desde o final de década de 1960 o cinema russo era uma atividade economicamente inviável, em virtude dos altos custos de produção e distribuição por salas de cinema de todas as 15 repúblicas socialistas e pelo baixo custo do ingresso, cerca de 30 copeques. Para a reconstituição detalhada dos custos de produção e desse período em particular ver Albéra (ALBÉRA; ESTÈVE, 2009) e sobretudo Marcel Martin (1993). 
Isto é, tardiamente, a Rússia e as demais repúblicas retomavam as discussões sobre cinema de autoral e de mercado já em curso no Ocidente.

Contudo, o principal tema do debate cinematográfico à época da Glasnost estava menos restrito à emergência de um cinema autoral - cujo paradigma quase único para esta geração de críticos e realizadores pré e pós-Glasnost estava na figura de Tarkóvski - que preso à necessidade urgente de aproximação do cinema russo de seu público. Isto é, o novo cinema russo, que então surgia, devia agora correr para o mercado. De arte de estado todopoderoso para artefato de mercado-todo poderoso.

0 artigo que melhor radiografa o impasse da filmografia russa posta entre mercado e cinema autoral, e sobretudo a luta pela conquista do mercado, isto é, por uma cinematografia popular da Glasnost, é devido a Mikhail Iampólski (1994). Intitulado Cinema sem Cinema (tradução nossa)7, estabelece que o divórcio entre o cinema russo e seu público devia-se, até então, entre outros fatores, a uma quase inexistência de filmes de gênero. Iampólski leva em conta a partilha entre filmes comerciais e filmes de arte vigente no estrangeiro. Embora, como aponta, esta divisão seja problemática, devido aos mútuos intercâmbios, e à distinção talvez equivocada de alta cultura e cultura de massas, ainda assim o cinema comercial, calcado em gêneros, permite a assimilação da verossimilhança narrativa, mesmo que com suas inversões e paródias. Comentando a deficiência de identificação no cinema russo, Iampólski recupera a noção de dupla identificação ${ }^{8}$ no cinema de Jean Louis Baudry (2008), primeiro com o aparato cinematográfico e depois com a personagem, mostrando como, no caso do cinema russo, a identificação tanto em nível primário quanto secundário é pouco eficiente. Isso se deveria à ausência de virtudes que ele chama propriamente cinemáticas, assim aludindo às teorias de Béla Balazs dos anos 1920, que apontava para a o primado da fruição estética e da fotogenia, tanto quanto a problemas da identificação com o personagem pela ausência não de bons autores, mas de tipos, de mitos, de um star system talvez - onde ele recupera a importância da sensualidade e da

\footnotetext{
7 IAMPÓLSKI, Mikhalil. Cinema without cinema. In: Brashinsky, Horton, Russian Critics on the cinema of Glasnost, Cambridge: Cambridge press 1994.

8 Iampólski (1994) comenta que esta dupla identificação é um fato consumado do cinema, sem citar diretamente a referência teórica que poderia, no entanto ser remetida à Jean Louis Baudry e seu clássico artigo- Cinema: efeitos ideológicos do aparelho de base (BAUDRY, 2008). Ironicamente, o que reclamava (e ansiava pelo inverso) Iampólski era justamente a falta de identificação dentro do cinema russo, exatamente o que era, ao contrário, condenado ideologicamente por Baudry.
} 
presença dos corpos na tela, realizando mesmo uma ponte com o Eisenstein de $O$ Encouraçado Potemkin (1925)9.

Ao longo do artigo, portanto, Iampólski (1994) deplora a situação do cinema russo em 1988, imputando-a a razões históricas - como o período de estagnação em que quase se criou uma espécie de gênero equivocado, o que ele chamou de filme industrial, ou filme de Fábrica, em que os conflitos limitavam-se a roteiros teleológicos bem ao estilo do realismo socialista, com os heróis do povo, salvando a fábrica do incêndio, a colheita da enchente, sempre num final utópico e apoteótico. ${ }^{10}$

Outros fatores, segundo o autor, seriam não a ausência de um bom roteiro estruturado, mas a confiança cega no verbal em detrimento do visual, isto é, como comentado, das virtudes propriamente fílmicas (daí o título do artigo) bem como problemas de ordem técnica que remetem, no fundo a uma incapacidade de conquistar verossimilhança e pela estratégia naturalista, auferir o verdadeiro ilusionismo, como os filmes clássicos americanos (IAMPÓLSKI, 1994).

É nesse contexto de liberalização do regime que surgem novos filmes que procuravam se colocar no mercado com uma renovação estética e temática face ao cinema soviético onde o contexto de censura e controle eram rigorosos. São citadas como referenciais produções como, Dias do Eclipse (1988), de Sokúrov, ao lado de Pequena Vera (1988), de Vasily Pichul, Taxi Blues (1990) de Pavel Lunguin, , Assa (1987), de Serguei Solovyev. O filme de Sokúrov é então considerado um dos mais importantes do período (BRASHINSKY; HORTON, 1994). Ele interessa a esta contextualização porque gerou reações opostas que espelham a situação em debate e portanto a posição de relativo isolamento em que o autor se colocou.

Este filme, outra adaptação literária pouco tradicional, no caso, de uma novela popular russa de ficção científica dos Irmãos Strugátsky ,base literária também de Stalker (1978) de Tarkóvski, intitulada Um Bilhão de Anos Antes do Fim do Mundo (1977), teve como co-roteiristas os próprios autores do livro (que após vê-lo pronto, assim como fizeram com Stálker, disseram que deles só havia o nome). Do ponto de vista de sinopse, o filme consiste

\footnotetext{
90 artigo é bastante prolífico em caminhos de pesquisa sugeridos e não é meu intento explorá-los, ou realizar uma síntese crítica. Trago aqui tão somente pontos que aludem para a questão do que pode ser entendido como uma separação do público do cinema: "The avalanche of films sans audience of course causes alarm” (IAMPOLSKI, 1994, pg .12).

${ }^{10}$ Referindo-se a esses filmes, Iampólski (1994) comenta sobre o estilo de interpretação dos atores quase sempre gritando e alude, não sem ironia, que alguns filmes do período soviético devem ter mais pessoas berrando que em todos os filmes da história do cinema. Mais interessante é a sugestão de que o conflito em uma sociedade perfeita (soviética) deveria se assemelhar a uma guerra, já que apenas o exterior era visto como obstáculo à felicidade - e a psicologia ficava abolida.
} 
na história de um jovem, 0 Dr. Dimitri Maliánov, que viaja para uma não nomeada província da Ásia Central a fim de escrever sua dissertação. Não o consegue, pois tudo conspira contra ele em uma espécie de pesadelo: o calor insuportável, pessoas estranhas, problemas diversos, intervenções de supostos Aliens e problemas com os doentes.

Enquanto parte da crítica elogiou o filme como metáfora do deslocamento e de uma Rússia em ruínas ${ }^{11}$, certa crítica apenas nele viu uma falsa adaptação, pretensamente artística, de um cineasta que acreditava ser tão interessante quanto Tarkóvski - aqui novamente colocado como o paradigma do autor russo de qualidade. 0 ataque mais espetacular, incisivo e, a levar-se em conta o título, irônico, foi escrito por Tatiana Móskvina que, em um texto denominado Um bilhão de anos antes do fim do cinema (tradução nossa) ${ }^{12}$, comenta que "eu acredito que esse diretor mais imita do que representa com autoridade a autoria em um filme" (MOSKVINA, 1994, p. 120, tradução nossa).13

Não cabe aqui discorrer sobre os argumentos desta análise crítica do filme, mas tão somente ressaltar que o tema - autor e cinema comercial - persistiam e eram vívidos na crítica da Glasnost, e que, paradoxalmente, isso votou o cinema de Sokúrov a um duplo isolamento.

\section{Sokúrov e a metáfora da Ilha}

De fato, se na época da estagnação, Sokúrov poderia emblematizar a luta do indivíduo contra o Estado, a observância maior à arte frente às totalitárias injunções de governo, no novo período da liberalização, inscrevia-se como um autor, assumindo a posição de herdeiro natural de Tarkóvski como o grande cineasta russo autoral. (KARAKHAN, 1994,)

0 fato é que, quando ocorre a Glasnost, o movimento inegável era pelo cinema comercial e a obra de Sokúrov continuaria a ser um corpo estranho no cinema de seu país, só que agora em relação à aproximação com o público. 0 autor colocava-se em isolamento, agora não mais dentro de um contexto de estado, mas sim de mercado. É nesse sentido, de

\footnotetext{
11 Ver sobretudo as análises de Maya Turovskaia (1994, pg.112-113) e Mikhail Yampólski (1994, pgs. 114-115). Já um autor de inspiração marxista, Frederick Jameson (1992) percebeu um contraponto interessante, inclusive do ponto de vista de cenografia, com Guerra nas Estrelas (1977), de Georges Lucas, vendo Jameson no filme de Sokúrov uma reflexão sobre a destruição do sistema soviético.

12 MOSKVINA, Tatyana. A billion years before the end of cinema. In: BRASHINSKY, Michael; HORTON, Andrew. Russian critics on the cinema of glasnost. Cambridge: Cambridge University Press, 1994. p. 116-120. Tradução nossa.

130 problema, frequentemente apontado na crítica, de filmes de Sokúrov parecerem imitar mais do que emprestar de certos autores - sobretudo Tarkovski - aparece também em várias resenhas do período e ainda atuais, revelando certo incômodo com o autor.
} 
isolamento, ainda que comunicante, que pode ser percebida em Sokúrov uma determinada poética que, por hipótese, metaforiza a noção de ilha, de isolamento circundante.

No percurso das realizações artísticas e das intervenções de Sokúrov, chama atenção a referência direta ou indireta ao conceito de ilha e às metáforas do isolamento. Ostróv Sokurova, ou em tradução literal do russo "A ilha de Sokúrov", por exemplo, é o exato título do website oficial do realizador, mantido com a curadoria do museu Hermitage, por Aleksandra Túchinskaia. Este site é também a principal fonte de referência sobre os filmes e conteúdos de acesso ao diretor ${ }^{14}$.

A ilha de Sokúrov foi também o nome de um programa de televisão que o cineasta dirigiu em 1998-1999, em que se discutia o lugar do cinema na contemporaneidade. Parece portanto muito assente que a noção de Ilha metafórica está bem documentada como aspecto pertinente à visão própria do diretor, pois ela mesma emblematiza o conjunto de sua obra através do site referencial. A própria obra maior do diretor, o filme Arca Russa (2002), apresenta 300 anos de história russa em uma tomada única, um longo plano sequência, conduzidos num diálogo do diretor em voz off com um personagem fantasmático, todo ele filmado no museu Hermitage em São Petersburgo, cujo último plano é justamente o rio Neva congelado - como se a arca russa metafórica estivesse encalhada ali, tal qual uma ilha no gelo ${ }^{15}$. Aqui cabe analisar este percurso e verificar como este aspecto de ilha, de isolamento, se inscreve em sua poética.

O primeiro filme de ficção de Sokúrov, A Voz Solitária do Homem (1978), anota esta mesma postura de solidão no coração do seu protagonista fílmico. A ideia de isolamento, metaforizada por uma ilha, está também presente na série de elegias fílmicas, dentre as quais especialmente Elegia Oriental (1996), onde uma ilha artificial é construída para abordar uma ilha mítica, brumosa, em que o protagonista narrador protagonizado por Sokúrov evoca sua viagem ao Oriente.

Neste filme, a voz off sussurrada de Sokúrov diz: "Estive sempre nesta ilha, me sinto aqui em casa" (ELEGIA ORIENTAL, 1996). Sentir-se em casa em uma ilha: assim, o tema da ilha parece se repetir como conteúdo expressivo do diretor. 0 que significará, portanto, esta ilha? Falar da ilha como metáfora será falar do espaço solitário; mas também será assinalar o paradoxo de um espaço de comunicação. A ilha é, assim, um lugar metafórico no

\footnotetext{
${ }^{14}$ Ver www.sokurov.spb.ru. Há uma versão em inglês deste website, contendo sinopses e notas de produção de todos os filmes do diretor e alguns registros fotográficos e diários.

15 Laymert García dos Santos (2002) chega a comparar a Arca Russa (2002) a uma Arca de Noé, para salvar as espécies, ao comentar o final do filme, com o Palácio de inverno cercado de mar por todos os lados. A bibliografia sobre o filme é ampla, comportando perspectivas diversas.
} 
imaginário ocidental; seu próprio radical latino (insula) inscreve um isolamento, uma separação. Mas, se nenhum homem é uma ilha, como escreveu o poeta John Donne (1623) no seu mais famoso texto ${ }^{16}$, Carlo Ginzburg (2004) em seu livro sobre as comunicações interculturais e a distância modifica a formulação ao assinalar que também "nenhuma ilha é uma ilha" (GINZBURG, 2004, p. 113). Pois a ilha é, primordialmente, o lugar da comunicação (cercada de águas por todos os lados) onde os aportes e as contribuições se fazem das formas mais insuspeitas e por vias de fluxo e refluxo com todas as outras ilhas do oceano. (GINZBURG, 2004. É justamente essa ideia de ilha como isolamento, porém comunicação, isto é, cercada por um contexto do qual faz parte e com o qual se relaciona, marcando uma independência, que acreditamos ser um sinal da poética do autor, onde independência/autoria porém participação/adesão coletiva encontram-se entrelaçados. Isto é, aqui se quer propor como hipótese que haveria uma marca de individualidade, isto é, uma ilha, a autoria em conflito primeiro com um estado imperial que se desagrega e depois com um mercado que nasce selvagem.

Esta autoria, que procura se comunicar sobretudo com outros autores e obras, é fortemente marcada pela presença do literário, como mais de um crítico já notou (ARNAUD, 2005). Não apenas o primeiro filme é uma adaptação de um autor russo (Platonov), mas Sokúrov já adaptou também Flaubert, Dostoievski, Goethe, Shaw, Strugátski - adaptações todas elas bastante livres - além de realizar um documentário com Soljenítsin. E mesmo quando a origem temática não é marcadamente uma obra literária, há sempre um esforço de enunciar a palavra, seja por uma voz off sussurrada do diretor - como por exemplo na obra prima Arca Russa (2002), Hubert Robert (1996), Elegia Oriental (1996), Vozes Espirituais (1995) e tantos outros - como muitas vezes a voz dos personagens fílmicos principiam por balbucios, por um tateio da emissão vocal, como no caso, por exemplo, do filme Mãe e Filho ( 1996), em que também diálogos de obras literárias são inseridas. Nesse sentido, uma interessantíssima correlação de suas obras, com a criação literária, tem sido feita por autores como Leonid Heller (2009), com a recuperação das concepções sobre cinema dos formalistas russos, sobretudo Boris Eikhenbaum.

Nas décadas de 20 e 30 do século XX, os formalistas russos estavam interessados em entender as diferentes artes no plano de suas linguagens e, nesse sentido, estavam particularmente empenhados em analisar a poética do cinema, do que resultou uma

\footnotetext{
${ }^{16 “ N o}$ man is an island, entire of itself; every man is a piece of the continent, a part of the main” In: Meditações - XVII (DONNE, 2007, p. 104).
} 
coletânea intitulada A Poética do Cinema surgida na então URSS em 1927. Seus autores procuravam encontrar o verbal no cinema, supondo uma contaminação dos códigos. Assim, por exemplo, a teoria do discurso interior do espectador de Bóris Eikhenbaum (1998) avaliava que o fluxo sintagmático do filme exigia a palavra, a reconstrução narrativa em linguagem pelo espectador, como se a palavra e o conceito emergissem do visual, nunca o eludindo. Isto é, se na literatura criava-se imagens pela palavra, no cinema criar-se-iam palavras pela imagem. Eikhenbaum entendia que o cinema constituía sintagmaticamente cine-frases e estas só podiam se validar com a construção dialógica e verbal do espectador. Eikhenbaum comentava ainda que o cinema jamais fora mudo, só não era audível ainda, e por isso não fazia sentido qualquer purismo de que o cinema seria apenas a arte da imagem, como era a crítica que se fazia sobre o uso de intertítulos, o uso da música e mais tarde o próprio som (EIKHENBAUM, 1998). Assim, para este autor tratava-se de fazer um cinema em que a participação do espectador era exigida, em clara oposição à leitura de que o cinema estaria fadado ao naturalismo. No seu entender, o uso cada vez maior de metáforas demonstrava a insinuação do verbal na construção do sentido. No mesmo paralelo, Heller (2009) vem a campo destacar que o literário tem sido recorrente não apenas em vários níveis nos filmes de Sokúrov, mas o autor ele mesmo sempre declara esta primazia da leitura, e da cultura literária.

Assim, em suma, esta "voz solitária do homem" constitui-se uma linha de investigação sobre a poética de Sokúrov, fazendo parte não apenas da sua gênese artística mas também de algum modo sobre os discursos que percorrem suas obras. Nesse sentido, cabe aqui a pergunta: por que esta voz se particulariza, ou em que consiste sua singularidade? Resumindo esta posição de singularidade, Birgit Beumers (2009), uma das maiores scholars do cinema russo declara:

A contribuição de Sokúrov para o cinema russo é única. Ele fica em uma posição solitária; seus filmes são co-produzidos com o Japão, Alemanha e outros países europeus. Ele é convidado para festivais internacionais, mas se distingue do mainstream da produção russa. (BEUMERS, 2009, p. 252, tradução nossa ${ }^{17}$ ).

\footnotetext{
17 No original: "Sokurov's contribution to Russian cinema is unique: he stands in a solitary position, as his films are coproduced with Japan, Germany, and other European countries. He is invited to international festivals but stands apart from the mainstream of Russian film production."
} 


\section{Conclusão}

Concluindo este artigo em que o tema da Ilha Sokuroviana é apontado como pista de investigação de sua poética, vale salientar que, devido à sua atividade proteiforme, parece ser bastante difícil encontrar um sentido único ou unificador de toda a sua obra.

Diane Arnaud (2005), autora da primeira tese de doutoramento sobre a obra de Sokúrov em 2005 - e cujo trabalho procura destacar outra chave do poético, o que a autora chama de figuras de enclausuramento - talvez formule de forma exemplar o conjunto de problemas dirigidos àqueles que desejam enfrentar análise poética e estética de Sokúrov:

O difícil acesso à sua criação, além das considerações contextuais, advém das aparentes contradições de sua obra monumental e protéica: ficção \ não-ficção, jornada individual/proposta coletiva, ideologia conservadora de autor/ inspiração humanista e vanguardista da forma fílmica. (ARNAUD, 2005, p. 8, tradução nossa ${ }^{18}$ ).

Em suma, a metáfora da ilha, isolada, porém comunicante por todos os lados, pode constituir-se em hipótese de trabalho interessante sobre a obra deste realizador de tantas contradições aparentes, em que o enclausuramento e seu contrário parecem podem ser vistas como variações do mesmo tema.

\section{Referências}

ALBÉRA, François; ESTÈVE, Michel (org.). Alexandre Sokourov. Paris: Editions Charles Corlet, 2009.

ARNAUD, Diane. Le Cinéma de Sokourov: figures d'enfermement. Paris: L'harmatan, 2005.

BAUDRY, Louis. Cinema: efeitos ideológicos do aparelho de base. In: XAVIER, Ismael(org.). A experiência do cinema. São Paulo: Graal, 2008. p. 383.

BAZIN, André. 0 que é o cinema. São Paulo: Cosac \& Naify, 2014.

BEUMERS, Birgit. A history of Russian cinema. New York: Berg, 2009.

BRASHINSKY, Michael; HORTON, Andrew (org). Russian critics on the cinema of glasnost. Cambridge: Cambridge University Press, 1994.

\footnotetext{
${ }^{18}$ No original: Le difficile accès à sa creation, au-delà des considerations contextuelles, provident également des contradictions apparentes de son oeuvre monumentale et protéiforme: fiction|non fiction, parcours individuel|propos collectif, idéologie conservatrice de l'auter $\backslash$ inspiration humaniste e recherches avant-gardistes de la forme filmique.
} 
CONDEE, Nancy. The Imperial Trace: recent russian cinema. Oxford: Oxford Press, 2009.

DIETSCH, Bruno. Alexandre Sokourov. Lausanne: L'age d'homme, 2005.

DONNE, John. Meditações. Tradução de Fabio Cyrino. São Paulo: Landmark, 2007. p.104.

EIKHENBAUM, Boris. Problemas de cine-estilística. In: ALBÉRA, François (org.). Los

Formalistas Rusos y el Cine. Barcelona: Paidós, 1998. p. 45-76.

GINZBURG, Carlo. Nenhuma ilha é uma ilha: quatro visões da literatura inglesa. São Paulo: Companhia das Letras, 2004. p. 113.

HELLER, Leonid. L'Horizon paisible de la fin du monde: Sokourov et la littérature russe. In: ALBÉRA, François; ESTÈVE, Michel (org.). Alexandre Sokourov. Paris, Editions Charles Corlet, 2009. p 49-63.

IAMPÓLSKI, Mikhail. Cinema whitout cinema. In: BRASHINSKY, Horton, Russian Critics on the cinema of Glasnost, Cambridge: Cambridge Press, 1994. p. 11-17.

IAMPÓLSKI, Mikhail. The world as a mirror for the other world. In: BRASHINSKY, Horton, Russian Critics on the cinema of Glasnost, Cambridge: Cambridge Press, 1994. p. 114115.

IAMPÓLSKI, Mikahil. Un cinéma de la disparité: Kairos et Histoire chez Sokourov. In: ALBÉRA, François; ESTÈVE, Michel (org.). Alexandre Sokourov. Paris: Editions Charles Corlet, 2009. p. 39-48.

JAMESON, Fredric. The geopolitical Aesthetic: cinema and Space in the world system. Bloomington: Indiana University press, 1992.

MACHADO, Álvaro (org.). Aleksandr Sokúrov. São Paulo: Cosac \& Naify, 2002.

MARTIN, Marcel. Le cinéma Soviétique de Khrouchtchev à Gorbatchev. Lausane: L'Age d'Homme, 1993.

KARAKHAN, Lev. Jobless prophets. In: BRASHINSKY, Michael; HORTON, Andrew. Russian critics on the cinema of glasnost. Cambridge: Cambridge University Press, 1994. p. 30-35.

MOSKVINA, Tatyana. A billion years before the end of cinema. In: BRASHINSKY, Michael; HORTON, Andrew. Russian critics on the cinema of glasnost. Cambridge: Cambridge University Press, 1994. p. 116-120.

PLATONOV, Andre. The River Potudam. Bristol, Bristol Classical Press, 1988.

SANTOS, Laymert Garcia dos. Entrando na Arca Russa. In: MACHADO, Alvaro (org.).

Aleksandr Sokúrov. São Paulo: Cosac \& Naify, 2002. p 64-103. 
SCHNAIDERMAN, Boris. Os escombros e o mito. A cultura e o fim da União Soviética. Companhia das Letras, São Paulo, 1997.

TUROVSKAYA, Maya. The days of Eclipse. In: BRASHINSKY,Michael; HORTON, Andrew.

Russian critics on the cinema of glasnost. Cambridge: Cambridge University Press, 1994. p. 112-113.

\section{Filmografia}

AMANTES DE MARIA, Os. Título original: Maria's lovers. Direção: Andrei Konchalovsk. EUA, 1984. $109 \mathrm{~min}$.

ARCA RUSSA. Título original: Russki kovtcheg. Direção: Alexandr Sokúrov. Russia, ficção, 2002. $99 \mathrm{~min}$.

ASSA. Título original: Acca. Direção: Sergei Solovyev. URSS, ficção, 1987.153 min.

AUTOMÓVEIS GANHAM CONFIANÇA, Os. Título original: Avtomobil 'nabiraet nadezhonost'. Documentário. URSS, Gorki TV , 1977. 35 min.

DIAS DO ECLIPSE. Título original: Dni zatménia. Direção: Alexandr Sokurov. URSS, ficção, 1988. 137 min.

ELEGIA de Moscou. Título original: Moskóvskaia eléguia. Direção: Alexandr Sokurov. URSS, Documentário, 1986. 88 min.

ELEGIA ORIENTAL. Título original: Vostótchnaia eléguia. Direção: Alexandr Sokurov. Russia, documentário, 1996. $45 \mathrm{~min}$.

GREVE, A. Título original: Stachka. Direção: Sergei Eisenstein. URSS, ficção, 1925.

HUBERT ROBERT, uma vida afortunada. Título original: Rober. Stchastlívaia zhin. Russia, documentário, 1996. 26 min.

POTEMKIN, Encouraçado. Título Original: Bronenosets Potemkin. Direção: Sergei Einsenstein. URSS, ficção, 1925. $75 \mathrm{~min}$.

MÃE E FILHO. Título original: Mat i syn. Direção: Alexandr Sokurov. Rússia, ficção, 1996. 67 $\min$.

MARIA, elegia camponesa. Título original: Maria, Krestiánskaia eléguia. Direção: Alexandr Sokurov. URSS, Documentário, 1978. 41 min.

MOLOCH. Título original: Mólokh. Direção: Alexandr Sokurov. Russia, ficção, 1999, 102 min. PEQUENA VERA. Título original: Malenkaia Vera. Direção: Vasili Pichul. URSS, ficção, 1988. $115 \mathrm{~min}$. 
SOL ENGANADOR, O. Título original: Utomlennye solntsem. Direção Nikita Mikhalkov. França/Rússia, ficção, 1994. 135 min.

SOL, O. Título original: Solnce. Direção: Alexandr Sokúrov. Russia, ficção, 2004. 110 min.

STALKER. Título original: Stalker. Direção: Andrei Tarkovski. URSS, 1979. 163 min.

TAURUS. Título original: Tieliéts. Direção: Alexandr Sokurov. Russia, ficação, 2001. 94 min.

TAXI BLUES. Título original: Taksi-byuz. Direção: Pável Lungin. Rússia, ficção, 1990. 110 min.

VERÃO DE MARIA VOINOVA, O. Título original: Leto Marii Voinovoi. Documentário para Gorki TV. URSS, 1975. 30 min.

VOZ SOLITÁRIA DO HOMEM, A.Título original: Odinóki golos tchloveka. Direção: Alexandr Sokurov. URSS, ficção, $1978.87 \mathrm{~min}$.

VOZES ESPIRITUAIS. Título original: Dukhóvnyie golossá. Russia, 1995. Documentário em 5 partes: $38 \mathrm{~min} ., 33 \mathrm{~min}$., $87 \mathrm{~min} ., 59 \mathrm{~min} ., 90 \mathrm{~min}$.

The island of Sokúrov in the cinema of Glasnost: isolation and communication as hypotheses of interpretation in the work of Alexandr Sokúrov

\begin{abstract}
The article formulates a short history of the work of the Russian filmmaker Alexandr Sokúrov, in the context of the so called cinema of "Glasnost", the period of dissolution of the Soviet Regime. It is about showing how it is marked by the need to establish authorship, first within an adverse state context, then within a market regime. It is inseparable from this to point out how it is still traversed by a certain dialectical tension between isolation and communication, to suggest the hypothesis of a poetic distinguished by the metaphorical idea of the island. Theoretical references cover the critical fortune available in Russia and abroad, especially the pioneering studies carried out internationally by François Albera and Diane Arnaud, and contributions from Russian formalists in the poetic field of the film, notably Boris Eikhenbaum.
\end{abstract}

\title{
Keywords
}

Cinema. Russian Cinema. Sokurov. Glasnost. 


\section{Autor para correspondência}

Marcos Kahtalian

marcosk@brain.srv.br

\section{Como citar}

KAHTALIAN, Marcos; MOTTA, Leda Tenorio da. A ilha de Sokúrov no cinema da Glasnot: isolamento e comunicação como hipóteses interpretativas da obra de Alexandr Sokúrov. Intexto, Porto Alegre, n. 52, e93920, jan./dez. 2021. DOI: : http://dx.doi.org/10.19132/1807-8583202152.93920

Recebido em 22/06/2019

Aceito em 01/10/2019 